\title{
Mesoporous Silica Nanoparticles for Bio-Applications
}

\author{
Violeta-Carolina Niculescu* \\ National Research and Development Institute for Cryogenics and Isotopic Technologies - ICSI, Râmnicu Vâlcea, Romania
}

Mesoporous materials with high specific surface, pores volume and unique pore size were recently intensively studied as bio-materials, such as carriers for controlled bio-active principles delivery. Mesoporous silica materials exhibit greater capacity for drugs loading and insure a controlled bio-active compound release if they are functionalized, in comparison with amorphous colloidal silica. Mesoporous silica nanomaterials have lately earned increasing interest also due to their substantial capability to be used in tumors treatment and imaging. Recently, functionalized mesoporous silica materials known a rapid development in imagistic and curative applications. This review summarizes the recent advancement in the obtaining and biological properties of mesoporous silica nanomaterials, emphasizing the synthesis methods and drug delivery application. Commonly used synthetic strategies are discussed, followed by a systematic review of applicability in optical and MRI imaging.

\section{OPEN ACCESS}

Edited by:

Laura Maria Vergani,

Politecnico di Milano, Italy

Reviewed by:

Philippe Boisse,

Institut National des Sciences

Appliquées de Lyon (INSA

Lyon), France

Gabriella Epasto,

University of Messina, Italy

*Correspondence:

Violeta-Carolina Niculescu

violeta.niculescu@icsi.ro

Specialty section:

This article was submitted to

Polymeric and Composite Materials,

a section of the journal

Frontiers in Materials

Received: 23 July 2019

Accepted: 31 January 2020

Published: 19 February 2020

Citation:

Niculescu V-C (2020) Mesoporous

Silica Nanoparticles for

Bio-Applications. Front. Mater. 7:36.

doi: $10.3389 /$ fmats.2020.00036
Keywords: bio-application, drug delivery, functionalization, mesoporous silica, nanomaterial

\section{INTRODUCTION}

In 1906, Paul Ehrlich introduced the term "magic bullet," referring to an antigen capability to specific select "side chains" on the cells surface (Strebhardt and Ullrich, 2008; Li et al., 2012). In the cytotoxic chemotherapy, the design of a targeted component is essential if an efficient dose of a drug must attack only the damaged region, without affecting healthy cells. Hypothetically, this "magic bullet" must contain a nanoscale delivery system able to specifically targeting tumor, avoiding premature degradation (Peer et al., 2007). This integrated concept could result in a controlled-release upon activation.

Various theranostic drugs have been developed over the past 30 years, the most clinically used being multifunctional liposomes and polymeric micelles. However, the aim of this investigation is to draw special attention to the use of silica-based mesoporous nanomaterials as drugs robust and tuneable delivery systems.

Nanotherapeutics have been intensively studied in the last years, as a consequence of the capability to be used as effective drug delivery frameworks with decreased unwanted secondary effects (Lin et al., 2012). Contrary to the classical therapies, nanomaterials can be designed properly to target affected sites (tumors) and selectively deliver their load. Until now, different nanomaterials (polymers, metal, metal oxide, etc.) have been obtained and used as systems for integrating active principles and diagnostic functions in a single nanomaterial, called multifunctional nanotheranostic (Sanvicens and Marco, 2008; Lammers et al., 2010; Xie et al., 2010).

The unstoppable nanotechnology development resulted in the design of various nanomaterials with important therapeutic potential. For example, there have been discovered many materials suitable for treating various pathologies (Anselmo and Mitragotri, 2015, 2016), such as: magnetic (Hao et al., 2010; Lin et al., 2012; Wu et al., 2016) or plasmonic compounds 
(Lin et al., 2012; Liu et al., 2016), that can be isolated excited with a magnetic field and light, resulting a thermic reaction able to induce cell death (Lin et al., 2012).

Mesoporous silica gained a raised interest, due to its extensive multi-functionality, based on its high specific surface, uniform and tuneable pore size, high pore volume, and facile functionalization (Rosenholm et al., 2011; Lin et al., 2012).

The first surfactant-assisted synthesis of MCM-41 mesoporous silica (Mobil Composition of Matter No. 41) was achieved by Mobil Company in 1992 (Kresge et al., 1992), but MCM-41 begun to be studied for bio-applications since 2001 as a matrix for drugs release (Vallet-Regi et al., 2001; Lin et al., 2012). Also, other studies reported silica derivates with reduced dimensions for drugs release (Cai et al., 2001; Fowler et al., 2001; Lin et al., 2012). Since then, extensive research have been carried out in order to improve nanosilica synthesis, its functionalization and to study in vitro/in vivo activity. Figure 1 reflects a scheme used for highlighting the development of mesoporous silica nanomaterials used in biomedical-applications (Lin et al., 2012).

First modified mesoporous silica nanomaterials for stimulireactive guided liberation of active compounds through chemically extractible nanoparticles as coatings were obtained in 2003 (Lai et al., 2003; Lin et al., 2012). Since then, research focused on the addition of different compounds to obtain various diagnostic or therapeutic effects, which include: controlled drug delivery (Lai et al., 2003; Schlossbauer et al., 2009; Shen et al., 2017) and targeting (Wang et al., 2010; Shen et al., 2017).

Multifunctional mesoporous silica with imaging capabilities were synthesized and reported in 2006 (Kim et al., 2006; Lin et al., 2006). Until now, various routes to incorporate imaging agents were designed, for example fluorophores (for fluorescence imaging, Lin et al., 2005; Wu et al., 2008), or superparamagnetic nanoparticles (Kim et al., 2006; Lin et al., 2006).

From 2008, in vivo investigations have been achieved for the identification of mesoporous silica biodistribution
(Kim et al., 2008; Lin et al., 2012), toxicity (Huang et al., 2011; Meng et al., 2011), and therapeutic effect (Kim et al., 2008; Meng et al., 2011).

Although these nanomaterials have gain an increased interest and proved their compatibility for bio-applications in the last 10 years, various aspects must be taken into consideration prior to be clinically used (Lin et al., 2012). For instance, if they are intravenous injected, the biodistribution depends on the particles diameters and surface properties, therefore, the concern must be targeted in the size and stability control under the biological environment $\left(37^{\circ} \mathrm{C}\right.$, highly salted or serum-containing media) before injection (He et al., 2010; Lin et al., 2012). Another aspect that must be taken into consideration is the toxicity of mesoporous silica nanomaterials, the adverse effects being carefully examined.

Various studies concentrated on in vitro drug delivery, controlled release, or toxicity of mesoporous silica materials (Rosenholm et al., 2010; He and Shi, 2011; Lin et al., 2011; Xu et al., 2012). This review will mainly emphasize advancement in the domain, underlining the emergent synthesis methods, strategies to improve mesoporous silica stability and biodegradability.

Nowadays, the chemotherapeutics delivery evolved, resulting nano-encapsulated drug formulations which can improve the pharmacological profile of the free drugs. However, mesoporous silica materials are gradually receiving interest due to their unique properties, such as well-established drug delivery properties (Vallet-Regi et al., 2007) and versatility for creating high-performing hybrid materials. Besides mesoporous silica, other multifunctional devices based on various nano-platforms were discovered (Soenen et al., 2011; Monnier et al., 2014; Chauhan et al., 2018; Hameed et al., 2018).

It is well-known that bulk silica is intensively used in food or cosmetic industry, indicating that it has low toxicity. FDA (US Food and Drug Administration) cataloged silica compound

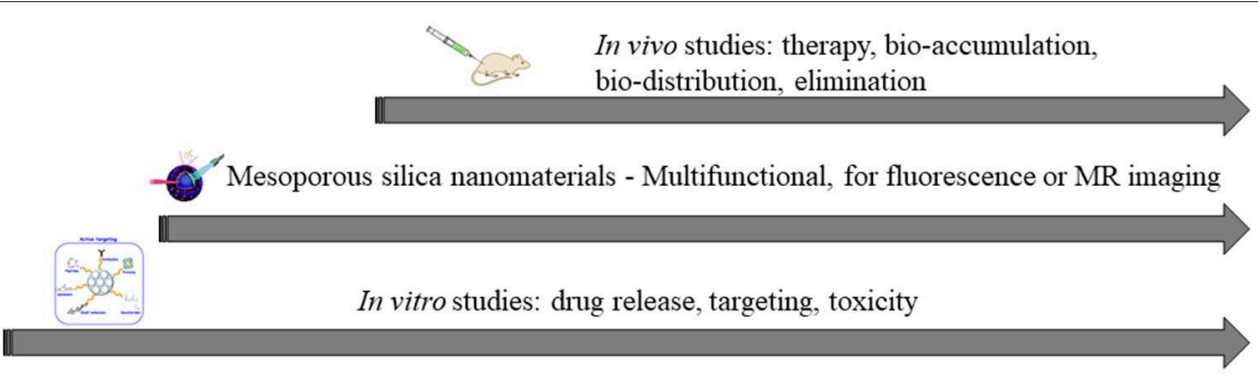

Mesoporous silica nanomaterials: synthesis, pores size and shape control, functionalization, stability studies

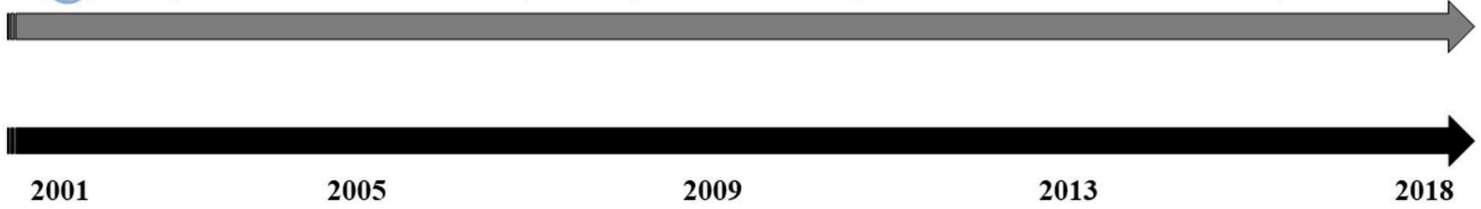

FIGURE 1 | Timeline scheme of mesoporous silica nanomaterials development for bio-applications. 


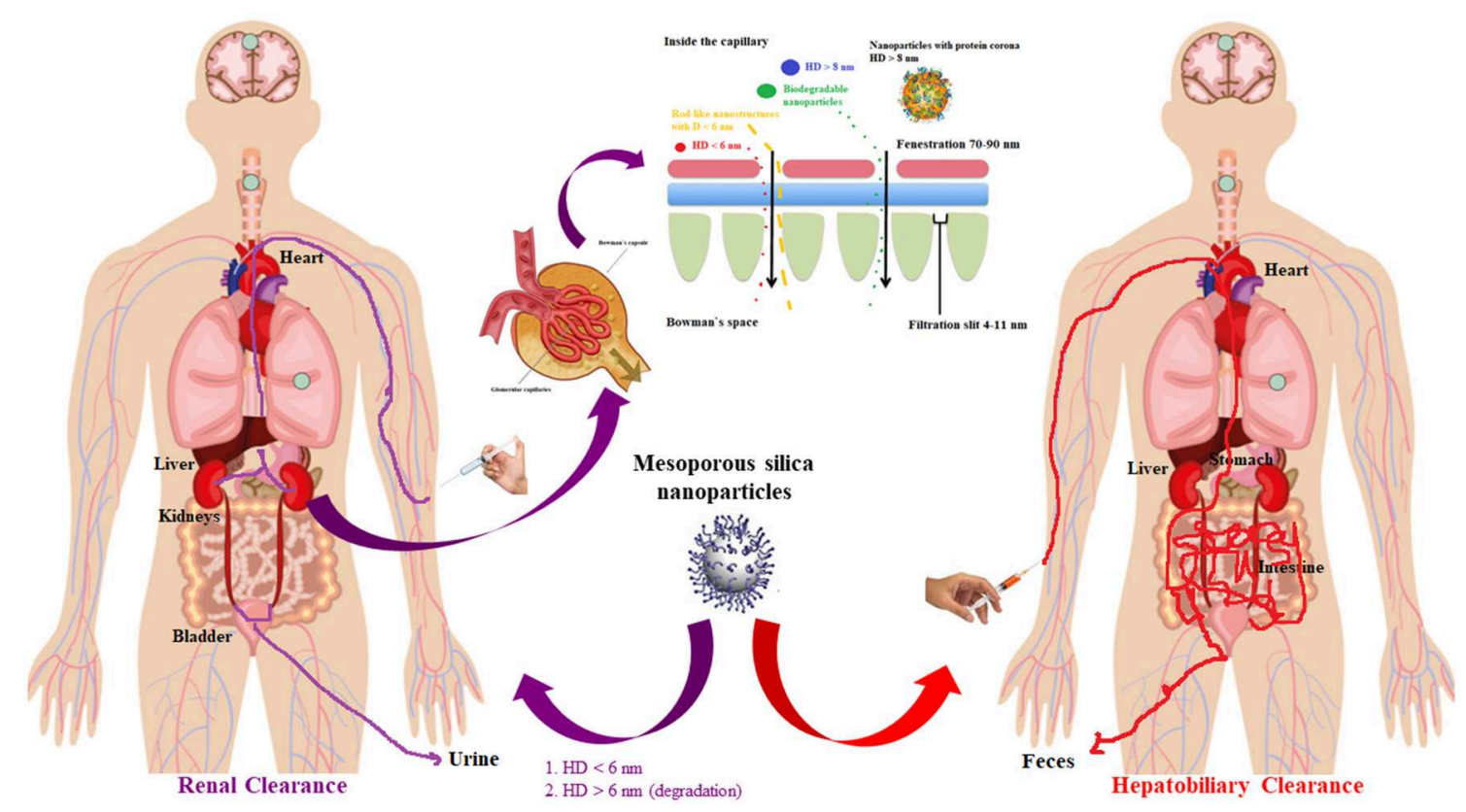

FIGURE 2 | Scheme of the main nanoparticles metabolic path and the glomerular filtration barrier.

as safe (ID Code: $14808-60-7)^{1}$. However, when a chemical compound is conceived like a nanomaterial, new limitations or safety risks arise, caused by their particles size (Lin et al., 2012). As an example, the interaction that appears between the nanoparticles and the cells, allowing their assimilation by the tumor cells, could result in unpredicted side effects in the healthy cells (Buzea et al., 2007).

For the mesoporous silica utilization in bio-approaches (Santos et al., 2015), the matrix degradation should be considered for the elucidation of the release kinetics, although for functionalized silica the parameter is harder to manage (Allen and Cullis, 2013; Sercombe et al., 2015).

The parameters and effects that must be monitored include, beside the degradability and the possibility to be eliminated (Figure 2), the size (Shang et al., 2014), shape (Huang et al., 2010; Li et al., 2015), pore volume (Li et al., 2018), and surface functionalization. Mesoporous silica with $100-200 \mathrm{~nm}$ nanoparticles dimensions are considered the optimal choice, preventing fast release (Li et al., 2012; Lin et al., 2012) and acute toxic effect (Napierska et al., 2009; Nishimori et al., 2009; Abbaraju, 2017), without aggregating on physiological fluids, blood capillaries and alveoli (McCarthy et al., 2012; Abbaraju, 2017).

Furthermore, the rod-like particles are considered more satisfactory than the spherical particles, as a consequence to easily achieve polyvalent interactions with the membranes (Huang et al., 2010; Meng et al., 2011; Lin et al., 2012).

${ }^{1}$ https://www.drugs.com/inactive/silicon-dioxide-colloidal-200.html （accessed July 28, 2019).
The interest on mesoporous silica for drug delivery depends on various factors the most important being the scale of the silica nanoparticles interaction with living systems. Before reaching the market, all nanomedicines must be industrially transferred, obviously, after clinical translation. Regarding the first step, the industrial technology is related to the scaling up process, involving also the reproducibility and the total costs, resulting in the ordinary barriers for commercialization. For example, the mesoporous silica nanoparticles are obtained in the lab from milligrams to grams of product, but the largescale batches production under Good Manufacturing Practices (GMP) conditions is a roadblock to their commercialization. Furthermore, reproducibility on their synthesis at small scale is relatively easy, but at the industrial scale is difficult. In this respect, the mesoporous silica clinical translation has been delayed, being blocked in the first milestone, whether or not the nanoparticles are reproducible and scalable, in terms of stability and high loading capacity. So far, researchers have not overlapped this milestone, although some advances were made. The next milestone to consider must be related to their potential toxicity and immunogenicity, which has been found to strongly depend on the surface functionalization. It has been demonstrated that mesoporous silica was perfectly biocompatible, in different animal models, in which toxicity has been discarded. However, until now, the mesoporous silica nanomaterials were not evaluated into any clinical trial, this being a delicate step, since many nanodrugs failed the clinical translation even before the clinical trials because of reiterative pitfalls.

Taking into account all the above-mentioned drawbacks and limitations, the integration of various features in a single entity could be considered a mirage. This review will highlight 
also the evolution of hybrid inorganic-silica nanomaterials with various bio-applications.

Taking into account all aspects, to currently categorize the mesoporous silica nanomaterials as appropriate tools for bioapplications, they must act in accordance with modification requirements with respect of morphology and surface, resulting in the minimization of the immune reply and enhance tissue/cell recognition-targeting.

\section{SYNTHESIS OF MESOPOROUS SILICA NANOMATERIALS}

At the beginning, scientists focused on improving the synthesis of mesoporous silica nanomaterials, trying to control their pore structure, size, and stability. Table 1 summarizes some typical synthesis methods for the mesoporous silica nanomaterials.

Typical scanning and transmission electron microscopy (SEM and TEM) images of mesoporous silica prepared by our group are presented in mesoporous Figure 3 (Miricioiu et al., 2019).

Mesoporous silica nanoparticles can be used as host materials for transporting therapeutics medicaments or encapsulation of molecules due to their biocompatibility, high loading capacity, the capability to attach target ligands for specific cellular recognition, or the design of well-defined and tuneable porosity (Tang et al., 2012; Hao et al., 2016; Vazquez et al., 2017). In order to achieve these, the morphology of the silica must be considered as one of the most important factors. One common synthesis method for mesoporous silica is the use of structure directing agents (neutral or charged surfactants) (Yuan et al., 2011; Vazquez et al., 2017). Generally, mesoporous silica are obtained from a silica precursor (or sodium silicate tetraethylorthosilicate-TEOS) by incorporating a surfactant, in an alcoholic solution under basic conditions (Pang and Tang, 2005; Hodali et al., 2016). Some studies focused on the mechanism of silica nanospheres and nanorods formation, by modifying the surfactant concentration (Lelong et al., 2008; Wang et al., 2013) and sol-gel dilution (Chen and Wang, 2012). The interaction between the $\mathrm{Si}-\mathrm{O}-\mathrm{Si} /$ species and the surfactant was monitored, and the pore diameters, shape, order, and morphology were correlated with the surfactant properties (size, length, etc.) (Vazquez et al., 2017). Also, the mesoporous silica obtaining was studied in non-alcoholic medium (Lelong et al., 2008; Chen and Wang, 2012; Vazquez et al., 2017), but the spherical particles formation was restricted by the surfactant amount (under 1 wt.\%). The specific surface area of the mesoporous silica materials was around $1,030-1,070 \mathrm{~m}^{2} / \mathrm{g}$, with a pore volume of $0.81-0.85 \mathrm{~cm}^{3} / \mathrm{g}$. The use of $\mathrm{EtOH}$ was considered, maintaining a fixed amount of CTAB (4.1 wt.\%) and ordered spherical and rod-like particles was obtained (Wang et al., 2013). The mesoporous silica material presented a specific surface area of $1,500 \mathrm{~m}^{2} / \mathrm{g}$ and a pore volume of $0.86 \mathrm{~cm}^{2} / g$. As it can be noticed, the dilution of the sol-gel results in the modification of the specific surface area and in the transformations of the particles morphology (from spherical to rod-like), highlighting that silica mesoporosity and morphology are related to the micelles formation and ordering.
A general synthetic route follows some typical steps: a silica source (tetraethyl orthosilicate-TEOS or sodium orthosilicate$\left.\mathrm{Na}_{2} \mathrm{SiO}_{6}\right)$ is mixed with a surfactant, then, a hydroxide $\left(\mathrm{NH}_{4} \mathrm{OH}\right.$ or $\mathrm{NaOH}$ ) is added, allowing that the silicate is hydrolyzed, surrounding the spherical micelles; finally, in order to silicate micelles self-assemble into cylinders, the mixture must be subjected to hydrothermal treatment (Lin et al., 2012). Surfactant can be removed by calcination, solvent extraction, or dialysis. First mesoporous silica with nanoparticles adequate for bioapplication were obtained in 2001 (Fowler et al., 2001; Lin et al., 2012). Afterwards, many investigations adopted the introduction of a co-solvent or another surfactant (Lin et al., 2012) for particles growth suppression, in order to get mesoporous silica nanomaterials with controlled size-Table 1 (Cai et al., 2001; Fowler et al., 2001; Lin and Tsai, 2003; Han and Ying, 2005; Berggren and Palmqvist, 2008; Sutewong et al., 2011).

The addition of surfactant during the synthesis generates a structure with many small pores (mesoporous structure) between 2 and $50 \mathrm{~nm}$, according to IUPAC notation (Assefa et al., 2016). Recently, templates as chitosan were used to inherent amino and hydroxyl functional groups, intermediating future functionalization of the mesoporous silica (Lalchhingpuii et al., 2017).

In order to produce silica nanomaterials with size suitable for bio-applications, a catalyzed sol-gel process has been employed. This process uses the organo-silane precursors which, by hydrolysis (1) and condensation (2), generating a new state (sol) (Brinker and Scherer, 1990; Mai and Meng, 2013):

$$
\begin{aligned}
& \mathrm{Si}(\mathrm{OR})_{4}+\mathrm{OH}^{-} \rightarrow \mathrm{Si}(\mathrm{OR})_{3} \mathrm{OH}+\mathrm{RO}^{-} \\
& \mathrm{SiO}^{-}+\mathrm{Si}(\mathrm{OR})_{4} \rightarrow \mathrm{Si}-\mathrm{O}-\mathrm{Si}+\mathrm{OH}^{-}
\end{aligned}
$$

For example, monodispersed nanosilica with particles size between 50 and 2,000 $\mathrm{nm}$ was obtained by Stober process, using the hydrolysis of tetraethylorthosilicate, catalyzed by ammonia, in an aqueous alcohol solution (Stober et al., 1968; Yanagisawa et al., 1990). The first sanvicens mesoporous silica nanomaterials were synthesized for catalytic applications (Yanagisawa et al., 1990; Kresge et al., 1992). Later, sub-micrometer-scaled MCM41 particles were prepared by a modified Stober process (Grun et al., 1997) and MCM-41 with $100 \mathrm{~nm}$ was synthesized by means of a diluted surfactant solution (Cai et al., 2001). Nano-silica with particle diameter under $50 \mathrm{~nm}$ were synthesized by applying two surfactants or dialysis (Suzuki et al., 2004; Li et al., 2012).

MCM-41 silica was typically obtained via a surfactant (hexadecyltrimethylmonium bromide) dispersed in ultrapure water; the mixture is stirred for several hours in ambient conditions; then the silica source, for example sodium silicate is added, stirring continuously the mixture. After that, the mineralizer, tetramethyl ammonium hydroxide is added, stirring the mixture another $30 \mathrm{~min}$ (Oshima et al., 2006). Then, the $\mathrm{pH}$ is adjusted to 10.5 , checking it after $15 \mathrm{~min}$. The mixture is agitated for $24 \mathrm{~h}$ and then it is subjected to hydrothermal treatment, by introduction into an autoclave 3-5 days, at 100$120^{\circ} \mathrm{C}$. The resulting mixture is filtered under vacuum, washed with water and dried (Miricioiu et al., 2019). After aging, 
TABLE 1 | An overview of some synthesis methods for mesoporous silica nanomaterials.

\begin{tabular}{|c|c|c|c|c|c|c|}
\hline Surfactant & Silica source & $\begin{array}{l}\text { Size control } \\
\text { method }\end{array}$ & $\begin{array}{l}\text { Particle size } \\
\text { (nm) }\end{array}$ & $\begin{array}{l}\text { Pore } \\
\text { structure }\end{array}$ & $\begin{array}{l}\text { Surfactant } \\
\text { removal }\end{array}$ & References \\
\hline $\begin{array}{l}\text { Hexadecyltrimethyl } \\
\text { monium bromide }\end{array}$ & $\begin{array}{l}\text { Tetraethyl } \\
\text { orthosilicate }\end{array}$ & $\begin{array}{l}\text { Water dilution and } \\
\text { neutralization }\end{array}$ & $60-100$ & $\begin{array}{l}\text { Ordered 2D } \\
\text { hexagonal }\end{array}$ & Calcination & Fowler et al., 2001 \\
\hline $\begin{array}{l}\text { Hexadecyltrimethyl } \\
\text { monium bromide }\end{array}$ & $\begin{array}{l}\text { Tetraethyl } \\
\text { orthosilicate }\end{array}$ & Dilution & $100-2,500$ & $\begin{array}{l}\text { Ordered 2D } \\
\text { hexagonal }\end{array}$ & Calcination & Cai et al., 2001 \\
\hline $\begin{array}{l}\mathrm{C}_{n} \text { TAMX } \\
\text { alkyltrimethyl } \\
\text { ammonium halide } \\
(n=14-18 ; \mathrm{X}=\mathrm{Br} \\
\text { or } \mathrm{Cl})\end{array}$ & Sodium silicate & $\begin{array}{l}\text { Low concentration } \\
\text { of surfactant-silica } \\
\text { source }\end{array}$ & $30-70$ & Disordered & Calcination & Lin and Tsai, 2003 \\
\hline $\begin{array}{l}\text { Pluronic P65, } \\
\text { P123, F108, F127 }\end{array}$ & $\begin{array}{l}\text { Tetraethyl } \\
\text { orthosilicate }\end{array}$ & $\begin{array}{l}\text { Surfactant } \\
\text { suppresses } \\
\text { particles growth }\end{array}$ & $100-300$ & $\begin{array}{l}\text { Ordered 3D } \\
\text { cubic }\end{array}$ & Calcination & Han and Ying, 2005 \\
\hline Pluronic P123 & $\begin{array}{l}\text { Tetraethyl } \\
\text { orthosilicate }\end{array}$ & $\begin{array}{l}\text { Water and salt } \\
\text { addition }\end{array}$ & $50-300$ & $\begin{array}{l}\text { Ordered 2D } \\
\text { hexagonal }\end{array}$ & Calcination & $\begin{array}{l}\text { Berggren and Palmqvist, } \\
2008\end{array}$ \\
\hline $\begin{array}{l}\text { Hexadecyltrimethyl } \\
\text { monium bromide }\end{array}$ & $\begin{array}{l}\text { Tetraethyl } \\
\text { orthosilicate and } \\
\text { (3-aminopropyl) } \\
\text { triethoxysilane }\end{array}$ & $\begin{array}{l}\text { Dye incorporation } \\
\text { and pore } \\
\text { expander addition }\end{array}$ & $100-220$ & $\begin{array}{l}\text { Ordered 3D } \\
\text { cubic }\end{array}$ & $\begin{array}{l}\text { Ethanolic acid } \\
\text { extraction }\end{array}$ & Sutewong et al., 2011 \\
\hline
\end{tabular}

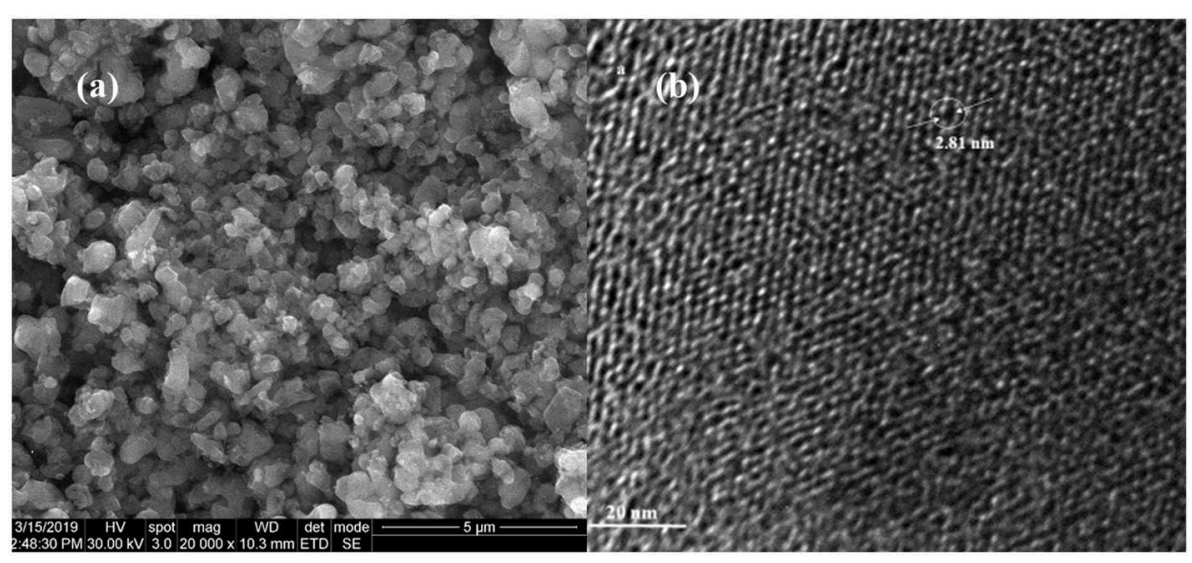

FIGURE 3 | Typical scanning electron (a) and transmission electron (b) microscopy for MCM-41 mesoporous nanosilica.

the resulting nanoparticles are calcined at $550-600^{\circ} \mathrm{C}$ in order to eliminate the excess of hexadecyltrimethylmonium bromide and to weaken the interactions between the surfactant and the formed silica (Li et al., 2012). Scanning and transmission electron microscopy certified the hexagonal arrangement after the hexadecyltrimethylmonium bromide removal (Figure 3; Miricioiu et al., 2019).

\section{FUNCTIONALIZATION OF THE MESOPOROUS SILICA NANOMATERIALS}

For the silica nanomaterials extension in the bio-domain, physical and chemical surface modifications have been applied. In this manner, the biocompatibility can be enhanced, the nonspecific adsorption can be prevented and functional groups for further biomolecule conjugation purposes can be provided. The most common surface modification includes layer by layer selfassembly (LSA) and chemical surface functionalization (Jafari et al., 2019).

The mesoporous silica nanomaterials can be functionalized by incorporation during the synthesis of metal or metal oxide nanocrystals (Figures 4a,b).

A heterogeneous mixture formed by the surfactant-coated metal nanocrystals in an organic solvent must be added to a solution of a surfactant (such as hexadecyltrimethylmonium bromide), in order to obtain a metal-functionalized silica ( $\mathrm{Li}$ et al., 2012). Then, a silicate source is added to the mixture to promote the condensation reaction, thus, gold, silver and iron oxide being embedded into the mesoporous silica (Coti et al., 2009; Thomas et al., 2010). This functionalized systems can possess various bio-activities, for example antimicrobial, assured by the dissolved metallic ions, plasmonic, or magnetic characteristics (Li et al., 2012). 


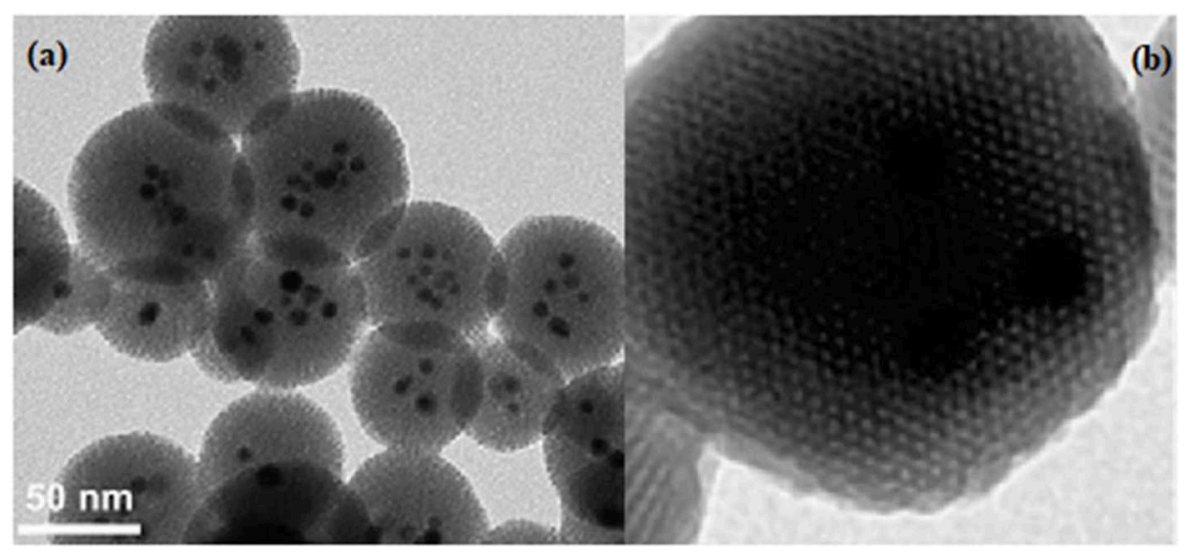

FIGURE 4 | Typical TEM image for (a) mixed iron-oxide and silver mesoporous silica and (b) Zn embedded in mesoporous silica.

To evaluate the substantial effect of different functionalization methods, research have been achieved to design colloidal core-shell mesoporous silica with various types of linear PEG (polyethylene glycol) modifications (Cauda et al., 2010). The silica functionalization can decrease the degradation rate comparing with the un-functionalized ones, the explication being the existence of the PEG matrix on the nanomaterial surface. PEG is hydrophilic, preventing in this manner the proteins adsorption and it reduces unwanted interactions of the physiological environment with the nanosilica (Yang et al., 2019).

Other research highlighted the silica surface functionalization with hydroxyl, carboxyl and PEG groups (noted OH-SiNPs, $\mathrm{COOH}-\mathrm{SiNPs}$, and PEG-SiNPs)and their bio-distribution and urinary excretion were studied (Figures 5A,B; He et al., 2008).

In vivo optical data from the urinary bladder showed that the nanomaterials were partially eliminated through renal route, highlighting that these modifications are independent on the renal elimination (Figure 5C; Yang et al., 2019). Nevertheless, PEG derivate manifested longer blood circulation and lower liver uptake compared to the hydroxyl and carboxyl derivates.

Various research investigated the SBA-15 silica functionalization. For studying the effect of surface functionalization upon deterioration behavior, Kim et al. explored the biodegradation of functionalized SBA-15, modified with hydroxyl, amine and carboxyl moieties on the surface (Choi et al., 2015; Yang et al., 2019). The carboxyl functionalized silica had the lowest degradation percentage. These studies indicated that the SBA-15 surface functionalization results in a reduction of the degradation rate then the neat silica, highlighting that the functionalization could affect the silica shell corrosion by connecting with the cations from the biological media for reducing the SBA-15 clearance rate (Choi et al., 2015; Yang et al., 2019).

A key factor that enables silica nanomaterials to be used in bio-applications is the capability to capture various loads in the pores channels, thus protecting the active compounds from enzymatic degradation ( $\mathrm{Li}$ et al., 2012). The mesoporous silica nanoparticles are usually charged by immersion in the active compound solution, the therapeutic being assimilated through adsorption. When silica surface is functionalized, the cargo is able to be controllable released at the targeted damaged tissue, no premature release in the bloodstream being observed, reducing any secondary effect and increasing the therapeutic efficiency ( $\mathrm{Li}$ et al., 2012). For example, Niculescu et al. reported SBA-15 mesoporous silica functionalized with amino groups from organic amines (aminopropyl triethoxysilane) for bio-active coordinative complex delivery (Niculescu et al., 2018). It was observed a linkage between the functional groups from the coordination compound and the amino groups from the silica surface, resulting an improvement of the hydrophobic interaction with the hydrophobic active principle (Niculescu et al., 2018). Once the degree of silylation is decreased by amination, the drug release rate will be improved.

\section{BIOCOMPATIBILITY}

In the context of bio-applications, mesoporous silica nanomaterials are generally considered biocompatible, with minimal non-specific or adverse effects. However, there are several factors that affect the silica biocompatibility, such as individual size, shape, and surface chemistry, until this moment the mesoporous silica biocompatibility remaining inconclusive (Hudson et al., 2008; Tang et al., 2012). This review take into account the current advances on how particles shape, size and surface properties influence the interaction with living cells (Jafari et al., 2019).

The biocompatibility, bio-distribution and clearance are influenced by the mesoporous silica nanomaterials morphology. For example, short-rod mesoporous silica is distributed predominantly at the liver level, whereas long-rod silica is caught in the spleen and manifest a reduced elimination rate (Huang et al., 2011; Jafari et al., 2019). The particles shape also influences cellular uptake, in vitro research reporting that the shape is independent of the endocytosis rates and dependent on endocytotic rate (Trewyn et al., 2008; Jafari et al., 2019).

Particles dimensions can influence the biological parameters (distribution, duration of blood circulation, or elimination rate) (Jafari et al., 2019). When the nanoparticles are intravenously delivered, they are predominantly directed to the liver and 


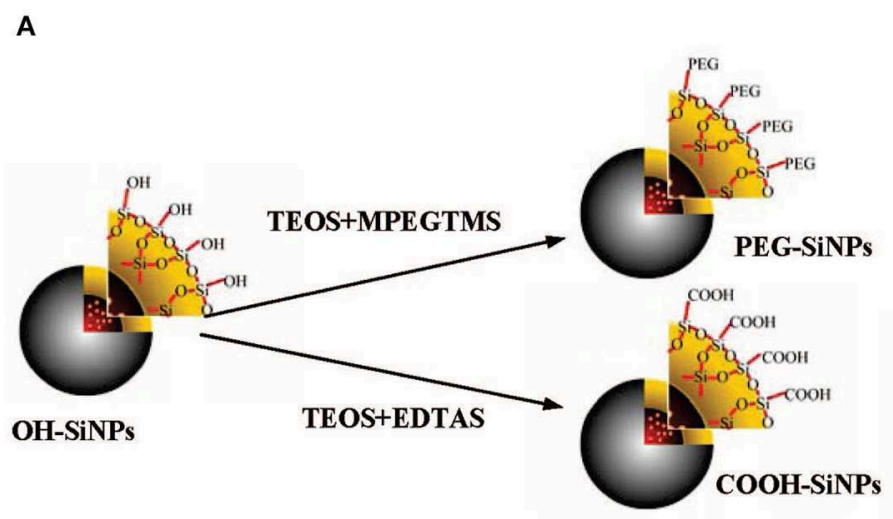

B
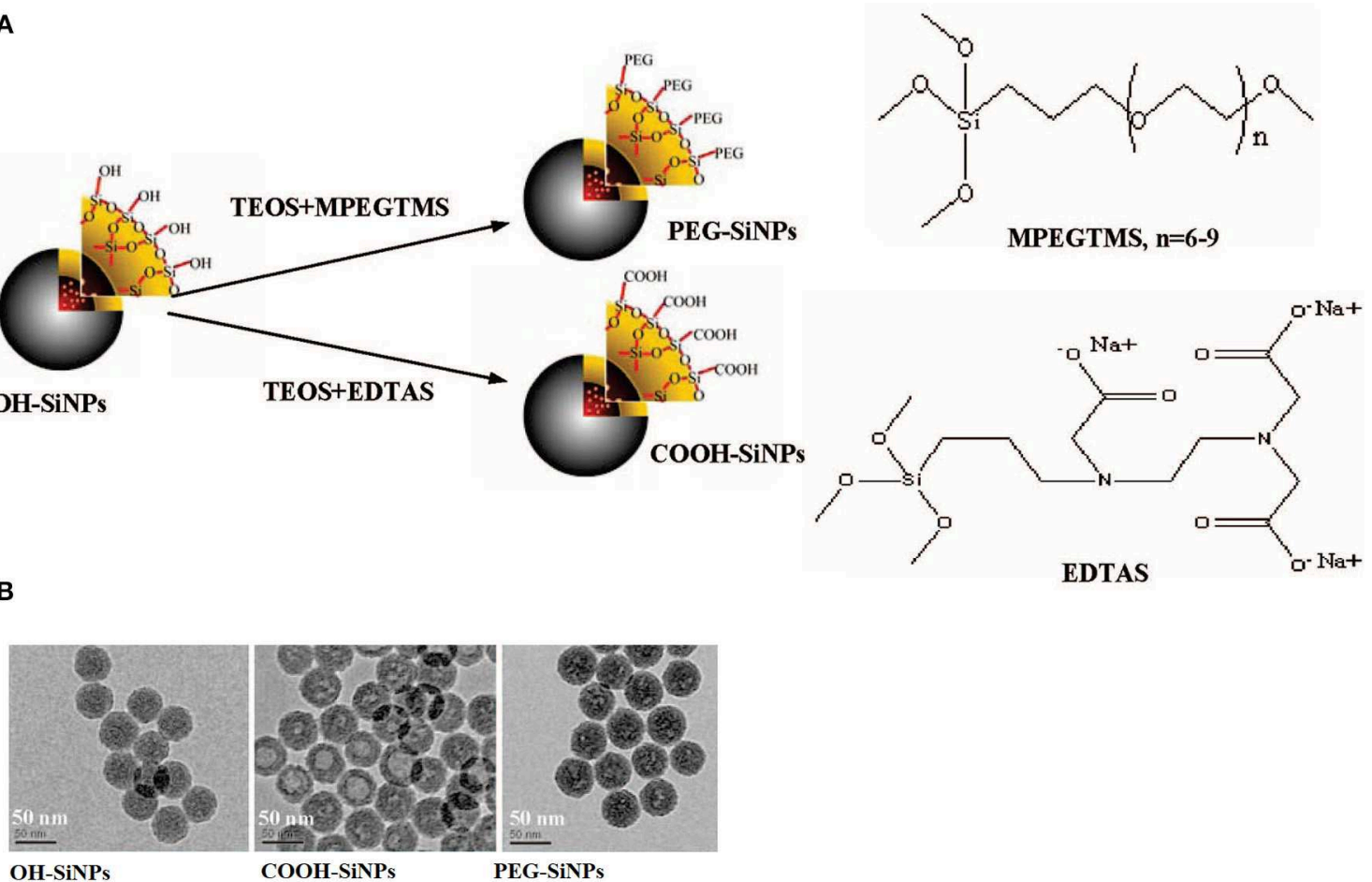

C
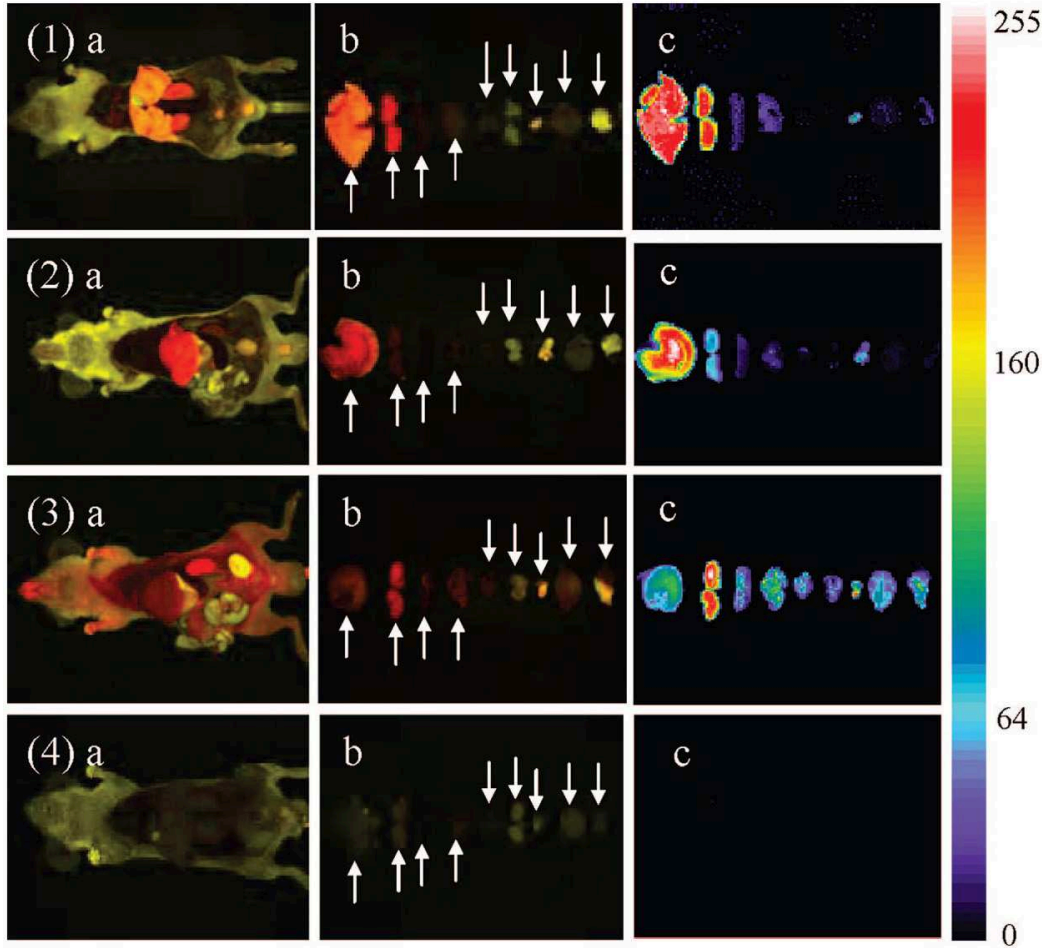

FIGURE 5 | Illustration (A) and TEM images (B) of three silica surface functionalized nanomaterials. (C) Ex vivo imaging of mice after intravenous injection, with various organs throughout necropsy after $4.5 \mathrm{~h}$, for treated mice (1) OH-SiNPs, (2) COOH-SiNPs; (3) PEG-SiNPs and untreated mice (4). Arrows represent from left to right: liver, kidney, spleen, lung, heart, spermary, bladder, brain, and muscle. Reproduced with permission He et al. (2008) Copyright 2008, American Chemical Society. 
spleen (Maleki and Hamidi, 2016). The silica nanoparticles with smaller size have a longer blood circulation lifetime (He et al., 2011). The mesoporous silica nanoparticles elimination by urine increases with the particles size, affecting the degradation rate and the biocompatibility. In vitro studies showed some toxicity for spherical $1,220 \mathrm{~nm}$ nanoparticles at concentration levels higher than $25 \mathrm{mg} / \mathrm{mL}$ (He et al., 2009).

Furthermore, the mesoporous silica nanomaterials biocompatibility may be influenced by the surface properties. Cationic charges on the surface may produce considerable immune reaction and cytotoxicity in contrast with the neutral and anion counterparts (Nel et al., 2009; Verma and Stellacci, 2010; Jafari et al., 2019), but they are favorable for transvascular transport in tumors. A negative zeta potential is considered related to the serum opsonin. The mesoporous silica biocompatibility is affected by the silanol groups at the outer layer, they negatively interacting with the biological molecules and destroying their structure (Slowing et al., 2009). Therefore, surface functionalization is essential for altering surface reactivity, in order to enhance the biocompatibility.

\section{BIO-APPLICATIONS}

\section{Drug Delivery}

Mesoporous silica nanomaterials present unique properties that qualify them as ideal nano-carriers for hosting, protecting and transporting drugs to the target site. The incorporation of targeting agents at the mesoporous silica surface is feasible for conducting them to the damaged tissue, growing the specificity and reducing unwanted secondary effects (Lin et al., 2012). Furthermore, multifunctional mesoporous silica nanomaterials can be design so that they possess synergistic therapeutic effects against diseased tissues. Most of the investigations on the mesoporous silica for drug delivery has been dedicated to cancer therapy.

The first study on silica type-MCM-41 for ibuprofen controlled release was achieved by the group of Vallet-Regi et al. (2001). The ibuprofen liberation profile highlighted a divergent behavior, which depends on the way that the active substance is loaded in the silica, but it is independent on the pore size. The in vitro experiments were achieved within constant state and the mixture was not stirred while the drug was released, limiting the diffusion at the particles surface (Wang, 2009). Later on, other study focused on the effect of pores size from the MCM41 on the ibuprofen release rate, revealing that, in a simulating body fluid (SBF) solution, it is decreasing direct proportional with the pores size decreasing in the domain of $2.5-3.6 \mathrm{~nm}$ (Horcajada et al., 2004).

Another important mesoporous material for therapeutics delivery systems is MCM-48 silica, recently attracting interest due to its matrix containing unique penetrating bi-continuous channels, which can be used when easy molecule accessibility and rapid transport is required. MCM-48 was investigated as carrier for ibuprofen and erythromycin (Izquierdo-Barba et al., 2005), the therapeutics release rate decreasing with the pores diameters and the surface chemical modification (Izquierdo-Barba et al., 2005).
Several investigations have been reported for drug delivery based on organic modified mesoporous materials. It is generally accepted that the functionalization influences the adsorption and delivery. MCM-41-based materials were modified with organic aminopropyl groups for the control of the ibuprofen release, the functionalization being decisive for the active compound adsorption and release (Munoz et al., 2003; Zeng et al., 2005).

From the same class of mesoporous silica, SBA-15 with large and controlled pore size has a high ordered hexagonal matrix (Zhao et al., 1998). The SBA-15 has pores with an average diameter around $6 \mathrm{~nm}$, larger than the MCM-41 pores diameter, which is around $3 \mathrm{~nm}$ (Niculescu et al., 2011). Due to this characteristic, it is generally assumed that SBA-15 will present less limitation for the release of bulk molecules. Calcined SBA15 was tested for the antibiotic amoxicillin delivery (Vallet-Regi et al., 2004), proven that the drug quantity incorporated within the silica network depends on the solvent, $\mathrm{pH}$, and amoxicillin concentration (Zhang et al., 2018). In the pure SBA-15, the Si$\mathrm{OH}$ groups exist only at the surface, forming weak hydrogen bonds with the active compound; this is the reason why silica is not strong enough to retain the drug and allow it to be delivered in a sustained manner (Hashemikia et al., 2015; Zhang et al., 2018). In order to surpass this milestone, functional groups were introduced on the surface of SBA-15 (Doadrio et al., 2006).

SBA-15 nanomaterials were post- and one-pot reaction modified with amino groups for ibuprofen (IBU) and bovine serum albumin (BSA) delivery (Song et al., 2005). Results showed that the drugs assimilation and delivery were extremely influenced by the SBA-15 silica surface properties. The ibuprofen delivery from the post-synthesis functionalized SBA-15 was efficiently controlled, because of the ionic interaction established between the ibuprofen carboxylic groups and the amino groups from silica surface. Recently, SBA-16 mesoporous silica was used for immobilization and release of two antiseptic organic complexes with $\mathrm{Zn}$ was tested in deionized water, not in a simulated body fluid (Zelenak et al., 2005). The complexes were liberated after $10 \mathrm{~h}$. Nevertheless, traces of the active compounds were found in the silica after $80 \mathrm{~h}$, as a consequence of the vigorous immobilization in the silica matrix.

MSU-type mesoporous silica has also been studied for drug delivery, such as penta-peptide drug, which is instantaneously delivered after the solid was washed with dimethylformamide (DMF) (Tourne-Peteilh et al., 2003; Wang, 2009). Ibuprofen and antipyrine can be delivered by carbonized mesoporous silicon microparticles, but no release profile was reported (Lehto et al., 2005).

\section{Cell Imaging and Photosensitizer Carrier}

The silica nanoparticles can be used in imaging, dye-doped materials being synthesized by Stöber or reverse micro-emulsion method. Monodispersed solid nanosilica with particle diameter between $50 \mathrm{~nm}$ and $2 \mu \mathrm{m}$ was obtained by Stöber method, which is a simple and efficient approach. The first well-dispersed colloidal silica spheres including fluorophores or dyes were 
synthesized by Vanblaaderen and Vrij (1992) and Abbaraju (2017). This study was extended for obtaining fluorescent coreshell nanosilica particles ( $C$ dots), which are water-soluble and non-toxic and having particle diameters between 20 and $30 \mathrm{~nm}$ (Ow et al., 2005; Abbaraju, 2017). These dots constitute biological exploration devices with increased bio-stability, dye quantum effectiveness and diminished energy transfer reaction, caused by the limited rotational motility of the dye captured in the $\mathrm{C}$ dots nucleus, assuring the preservation against a dissolution medium effect or molecular quenchers (Burns et al., 2009; Abbaraju, 2017). FDA approved the use of the $C$ dots in human clinical trial in 2011, the study showing that the nanoparticles were harmless in human use, without any traces after renal elimination (Abbaraju, 2017).

The reverse micro-emulsion method for obtaining dye-doped nanosilica particles involves the use of water, surfactant and oil (Jin et al., 2011). The silica precursor's hydrolysis, condensation, and the formation of dye trapped nanoparticles occur at the surfactant-oil interface, to form fluorescent nanoparticles. By using this method, monodispersed silica nanoparticles with the diameters of 30-60 nm were obtained (Santra et al., 2001a,b; Bagwe et al., 2004; Sanvicens and Marco, 2008; Yoo and Pak, 2013). In 2004, a modified micro-emulsion method was reported for the incorporation of organic dye into silica nanoparticles (Zhao et al., 2004). The same approach was applied for obtaining hybrid silica nanoparticles doped with $\mathrm{Pb}$-Se quantum dots for cell imaging, their toxicity being lowered by individual or multiple covering of the silica (Tan et al., 2007; Abbaraju, 2017).

Moreover, hollow nanosilica containing vast cavity and mesopores were used for optical magnetic resonance imagistic, positron emission tomography (PET) (Suschek et al., 2002; Abbaraju, 2017) and ultrasound imaging (Shi et al., 2013).

Photodynamic therapy is a photosensitizer-based tumor ablative treatment, followed by the tumor local radiation at a specific wavelength in order to activate the photosensitizer (Suschek et al., 2002; Abbaraju, 2017). After activation, it shifts the energy to molecular oxygen, producing reactive oxygen entities with cytotoxic effect, which are able to oxidize the target cellular macromolecule, resulting in the tumor cell removal (Figure 6; Lucky et al., 2015).
Mesoporous silica nanomaterials have also been employed as vehicles for fluorescent agents, being optically transparent due to their nanoscale particle size, not disturbing the emission of fluorescent agents. Taking into account that quantum dots can be easily oxidized, exhibiting fluorescence, PEGylated liposomecoated quantum dots-mesoporous silica were developed the oxidation prevention and the dispersion stability improvement (Pan et al., 2011; Wang et al., 2015). For example, the in vitro study of cadmium ions as quantum dots highlighted that the liposome-modified mesoporous silica prevented the quantum dots degradation (Pan et al., 2011).

An effective biomedical tool is considered the magnetic resonance imaging (MRI), providing the capacity to noninvasively get anatomic and functional data with high resolution (Wang et al., 2015). Mesoporous silica nanomaterials-based magnetic resonance contrast agents exhibit an increased sensitivity due to their high specific surface, providing increased payloads of the active magnetic centers (Wartenberg et al., 2013; Cha and Kim, 2019). Moreover, silica mesoporous structure provides easy access into the magnetic center. Mesoporous silica nanomaterials functionalized with targeted ligands may be efficiently conducted to damaged tissue for diagnostic goals, the accumulation of these nanomaterials-based magnetic resonance contrast agents at the selected site conferring an augmented imaging susceptivity (Wang et al., 2015).

Mesoporous silica nanoparticles are also used for application in photodynamic therapy, being vectors due to their flexible synthesis, porosity and the matrix capacity to absorb the light (Abbaraju, 2017). For example, there were prepared organically modified nanosilica particles for the retention of 2devinyl-2-(1-hexyloxyethyl)-pyropheophorbide (HPPH), which is a photosensitizer used in phase I/II of clinical trials for treating esophageal cancer (Roy et al., 2003; Abbaraju, 2017). The entrapment of the photosensitizer into mesoporous silica nanoparticles can conduct to the discharge from the nanocarrier, inducing reduced efficiency. Some mesoporous silica nanomaterials were obtained for combined photodynamic and photothermal therapy, by using the release of carboxy aluminum phthalocyanine with small $\mathrm{Pb}$ nanosheets (Zhao et al., 2014; Abbaraju, 2017). The mesoporous silica nanomaterials covalently bond the photosensitizer, while the $\mathrm{Pb}$ electrostatically covered

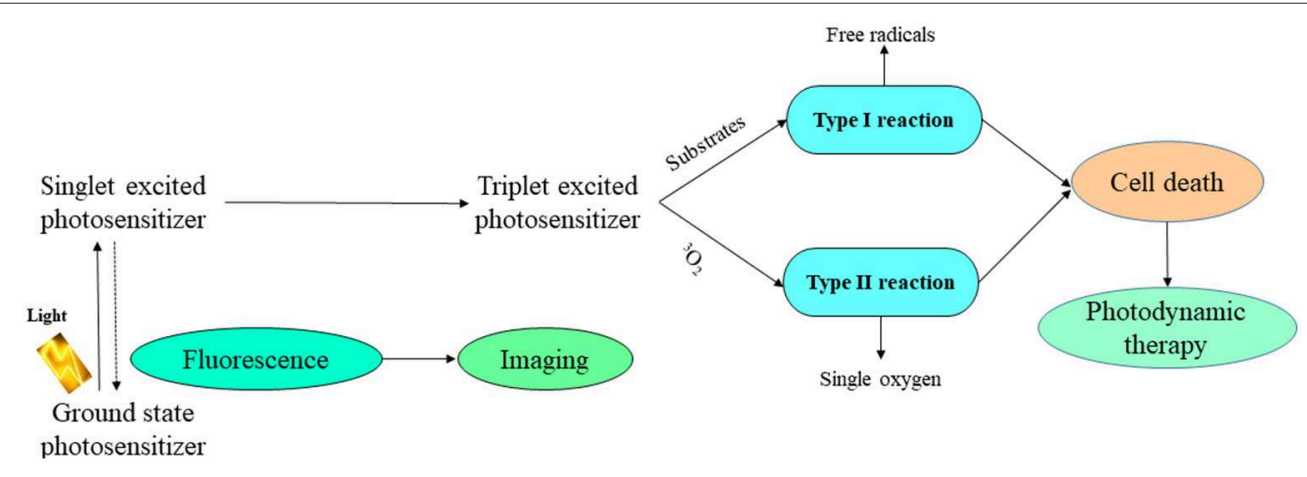

FIGURE 6 | Schematic photodynamic reaction. Adapted with permission Lucky et al. (2015) Copyright 2015, American Chemical Society. 
the silica surface. The HeLa-type cervical cancer cells viability decreased with $65 \%$ after the administration of functional nanocomposites, the effect being significant than the individual treatment (Abbaraju, 2017).

\section{Mesoporous Silica Nanomaterials in Vaccines}

The actual challenge in vaccines includes the induction of strong and safely immune-protective response in the host at low cost. Mesoporous silica nanomaterials can be used as an antigen carrier due to antigen preservation and its delivery to presenting cells (Kapczynski et al., 2012; Abbaraju, 2017).

For example, SBA-15-type nanomaterial possesses enhanced immunogenicity and immune reaction than $\mathrm{Al}(\mathrm{OH})_{3}$, in vitro macrophages studies showing that silica manifested increased phagocyte intake and minimal interaction with the cells (Carvalho et al., 2010; Abbaraju, 2017). Furthermore, the highest concentration of SBA-15 also conducted to a significant increase of the cells number, creating interleukin(IL)- 4 and interleukin(IL)-13 and, generating a heterogeneous reaction of both Th1-type and Th2-type cytokines (Abbaraju, 2017).

Mesoporous silica rods were tested in adjusting the immune cells and potential application as a vaccine matrix to induce adaptive immune reaction (Kim et al., 2015; Abbaraju, 2017). In vivo tests showed that mice immunized with full mesoporous silica rods vaccine manifested important growth of Thy $1.2^{+}$ leukemic cells, inducing increased expression of the Peripheral blood $\mathrm{CD}^{4+} \mathrm{CXCR}^{5+} \mathrm{T}$ helper cell clonal and $\mathrm{T}$ follicular helper cells differentiation (Kim et al., 2015). The silica surface modification effect upon immune cell activation was studied (Abbaraju, 2017). The mesoporous silica nanomaterials were modified with poly(ethylene glycol) (PEG) and poly(ethylene glycol) (PEG)/arginine-glycine-aspartic (RGD) and they were investigated in the immune cell adhesion and infiltration, the PEG derivate inducing higher CD86 expression than the RGD derivate (Abbaraju, 2017). Also, the PEG-RGD derivate exhibited lower inflammatory effect than the PEG-one.
However, the impact of all the crucial factors in adjusting the immune reaction was not completely elucidated. The effect of nanomaterials pores and particles size on immunological properties was studied by orally administration to mice, using Bovine serum albumin as model adjuvant (Wang et al., 2012). Three types of nanosilica particles with various particles diameters $\{\mathrm{S} 1,[\mathrm{~S} 2$ and 1-2(SBA-15)] $\}$ were applied, the Immunoglobulin $G$ antibody from the plasma after oral administration of bovine serum albumin-loaded S1, S2, SBA-15 being in the sequence SBA- $15<$ S2 $<$ S1 (Abbaraju, 2017).

Also, the influence of particle size on targeting dendritic cells was studied, demonstrating that the particles smaller than 20$30 \mathrm{~nm}$ in diameter can straight get to dendritic cell. Figure 7 presents the silica nanoparticles delivery into lymph nodes. Nevertheless, particles with diameters higher than $20 \mathrm{~nm}$ can be phagocyted and the dendritic cells uptake is also presented (Navarro-Tovar et al., 2016).

On the other hand, silica nanomaterials were also used for DNA vaccines delivery, relying on the transitory manner of the intended antigen in the host cells (Navarro-Tovar et al., 2016). Silica nanomaterials-DNA exhibited a clear enhancement in the immunogenicity, in contrast with DNA at a reduced magnitude as against the conventional vaccine. Silica-based vaccine also manifested increased proliferative responses, suggesting that silica nanomaterials can be considered as good delivery systems for the DNA vaccines, stimulating cellular and humoral reactions. This perspective for the distribution by mucosal routes constitutes an important target, due to the advantages of mucosal immunization such as easy administration and immune profiles.

\section{CONCLUSIONS}

Various types of nanosystems for cancer-targeted imaging and therapy were developed in the last decade. Among them, silica-based nanomaterials have been extensively synthesized, due to their non-toxic nature and facile chemistry for surface functionalization. The state-of-the-art reflected that

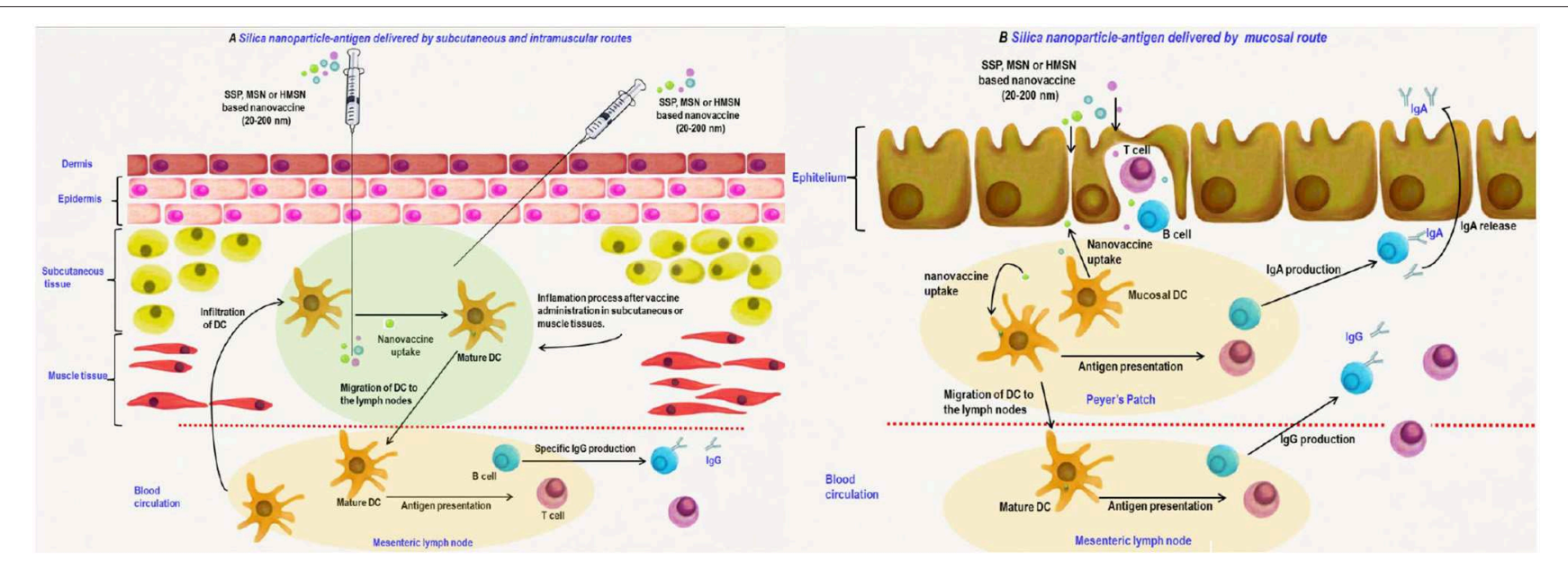

FIGURE 7 | Silica nanomaterials-based vaccines delivery by parenteral (A) and mucosal (B) routes. Adapted with permission Navarro-Tovar et al. (2016) Copyright 2016, Taylor \& Francis. 
materials based on nanosilica constitute fascinating media for new vaccines design, insuring the antigen conjugation (Cassano et al., 2017) and cellular adaptive immune responses. Mesoporous silica nanoparticles have been used in clinical trials for diagnostic purposes and drug delivery. The toxicity of these nanomaterials should be further investigated and evaluated at the clinical and pre-clinical levels. Concluding, the utilization of silica nanoparticles is significantly influencing the medicine domain, by obtaining new compounds to fight epidemiologic diseases.

This review drew special attention the main progress in drug delivery and bio-applications (Wang et al., 2015) of mesoporous silica nanomaterials. Mesoporous silica nanomaterials have attractive characteristics, such as a large specific surface, uniform and tuneable pores, increased pore volume, and decreased mass density (Kumar et al., 2018). They were intensively studied for drug delivery since 2000, to provide the improvement of the drug loading capacity and in vivo targeting efficiency, decreasing the unwanted effects on healthy organs. Due to their versatile mesoporous structure and porosity, they possess important advantages, for example, as drug delivery system, the release of the cargo is well controlled. Also, magnetic and luminescent mesoporous silica nanomaterials provide the simultaneous bioimaging and drug delivery.

\section{REFERENCES}

Abbaraju, P. L. (2017). Mesoporous Silica Nanoparticles for Biomedical Application. Aust Institute for Bioengineering \& Nanotechnology Institution; The University of Queensland. Available online at: https://espace.library.uq.edu.au/ view/UQ:681687 (accessed July 20, 2019).

Allen, T. M., and Cullis, P. R. (2013). Liposomal drug delivery systems: from concept to clinical applications. Adv. Drug Deliv. Rev. 65, 36-48. doi: 10.1016/j.addr.2012.09.037

Anselmo, A. C., and Mitragotri, S. (2015). A review of clinical translation of inorganic nanoparticles. AAPS J. 17, 1041-1054. doi: 10.1208/s12248-015-9780-2

Anselmo, A. C., and Mitragotri, S. (2016). Nanoparticles in the clinic. Bioeng. Transl. Med. 1, 10-29. doi: 10.1002/btm2.10003

Assefa, D., Zera, E., Campostrini, R., Soraru, G. D., and Vakifahmetoglu, C. (2016). Polymer-derived SiOC aerogel with hierarchical porosity through HF etching. Ceram. Int. 42, 11805-11809. doi: 10.1016/j.ceramint.2016. 04.101

Bagwe, R. P., Yang, C., Hilliard, L. R., and Tan, W. (2004). Optimization of dyedoped silica nanoparticles prepared using a reverse microemulsion method. Langmuir 20, 8336-8342. doi: 10.1021/la049137j

Berggren, A., and Palmqvist, A. E. C. (2008). Particle control of colloidal suspensions of mesostructured silica. J. Phys. Chem. C 112, 732-737. doi: $10.1021 /$ jp0766858

Brinker, C. J., and Scherer, G. W. (1990). Sol Gel Science: The Physics and Chemistry of Sol Gel Processing. San Diego, CA: Academic Press, Inc.

Burns, A. A., Vider, J., Ow, H., Herz, E., Penate-Medina, O., Baumgart, M., et al. (2009). Fluorescent silica nanoparticles with efficient urinary excretion for nanomedicine. Nano Lett. 9. 442-448. doi: 10.1021/nl803405h

Buzea, C., Pacheco, I. I., and Robbie, K. (2007). Nanomaterials and nanoparticles: sources and toxicity. Biointerphases 2, MR17-MR71. doi: 10.1116/1.28 15690

Cai, Q., Luo, Z.-S., Pang, W.-Q., Fan, Y.-W., Chen, X.-H., and Cui, F.-Z. (2001). Dilute solution routes to various controllable morphologies of MCM41 Silica with a basic medium. Chem. Mater. 13, 258-263. doi: 10.1021/cm99 $0661 z$
However, significant milestones must be addressed, for example, obtaining novel multifunctional mesoporous silica nanomaterials with controllable drug release, which can also be supervised via on line bioimaging in the target tissue (Wang et al., 2015). Also, more comprehensive and detailed toxicity tests are required before the mesoporous silica nanomaterials may be used in human patients. In order to design mesoporous silica nanomaterials appropriate in biomedical applications with no side effects, intensive in vivo tests are still required.

\section{AUTHOR CONTRIBUTIONS}

$\mathrm{V}-\mathrm{CN}$ conceived and designed the study, contributed to the collection of data, performed the data interpretation, and the manuscript writing.

\section{FUNDING}

This research have been financed by the Romanian Ministry of Scientific Research and Innovation, under Contract no. 9N/2019 NUCLEU Program, Project PN $19 \quad 1103 \quad 01-$ Studies on the obtaining and improvement of the acido-basic properties of the nanoporous catalytic materials for application in wastes valorization.

Carvalho, L. V., Ruiz, R., de, C., Scaramuzzi, K., Marengo, E. B., Matos, J. R., et al. (2010). Immunological parameters related to the adjuvant effect of the ordered mesoporous silica SBA-15. Vaccine 28, 7829-7836. doi: 10.1016/j.vaccine.2010.09.087

Cassano, D., Pocoví-Martinez, S., and Voliani, V. (2017). Ultrasmall-in-nano approach: enabling the translation of metal nanomaterials to clinics. Bioconjug. Chem. 17, 4-16. doi: 10.1021/acs.bioconjchem.7b00664

Cauda, V., Argyo, C., and Bein, T. (2010). Impact of different PEGylation patterns on the long-term bio-stability of colloidal mesoporous silica nanoparticles. J. Mater. Chem. 20, 8693-8699. doi: 10.1039/c0jm01390k

Cha, B. G., and Kim, J. (2019). Functional mesoporous silica nanoparticles for bio-imaging applications. Wiley Interdiscip Rev. Nanomed. Nanobiotechnol. 11:e1515. doi: 10.1002/wnan.1515

Chauhan, D. S., Prasad, R., Devrukhkar, J., Selvaraj, K., and Srivastava, R. (2018). Disintegrable NIR light triggered gold nanorods supported liposomal nanohybrids for cancer theranostics. Bioconjug. Chem. 29, 1510-1518. doi: 10.1021/acs.bioconjchem.7b00801

Chen, B., and Wang, Z. (2012). In vitro and in vivo evaluation of ordered mesoporous silica as a novel adsorbent in liquisolid formulation. Int. J. Nanomed. 7, 199-209. doi: 10.2147/IJN.S26763

Choi, Y., Lee, J. E., Lee, J. H., Jeong, J. H., and Kim, J. (2015). A biodegradation study of SBA-15 microparticles in simulated body fluid and in vivo. Langmuir. 31:6457. doi: 10.1021/acs.langmuir.5b01316

Coti, K. K., Belowich, M. E., Liong, M., Ambrogio, M. W., Lau, Y. A., Khatib, H. A., et al. (2009). Mechanized nanoparticles for drug delivery. Nanoscale 1, 16-39. doi: 10.1039/b9nr00162j

Doadrio, J. C., Sousa, E. M. B., Izquierdo-Barba, I., Doadrio, A. L., Perez-Pariente, J., and Vallet-Regi, M. (2006). Functionalization of mesoporous materials with long alkyl chains as a strategy for controlling drug delivery pattern. J. Mater. Chem. 16, 462-466. doi: 10.1039/B510101H

Fowler, C. E., Khushalani, D., Lebeau, B., and Mann, S. (2001). Nanoscale materials with mesostructured interiors. Adv. Mater. 13, 649-652. doi: 10.1002/1521-4095(200105)13:9<649::AID-ADMA649>3.0.CO;2-G

Grun, M., Lauer, I., and Unger, K. K. (1997). The synthesis of micrometerand submicrometer-size spheres of ordered mesoporous oxide MCM-41. Adv. Mater. 9, 254-257. doi: 10.1002/adma.19970090317 
Hameed, S., Bhattarai, P., and Dai, Z. (2018). Cerasomes and Bicelles: hybrid bilayered nanostructures with silica-like surface in cancer theranostics. Front. Chem. 6:127. doi: 10.3389/fchem.2018.00127

Han, Y., and Ying, J. Y. (2005). Generalized fluorocarbon-surfactant-mediated synthesis of nanoparticles with various mesoporous structure. Angew. Chem. Int. Ed. 44, 288-292. doi: 10.1002/anie.200460892

Hao, N., Li, L., and Tang, F. (2016). Shape matters when engineering mesoporous silica-based nanomedicines. Biomater. Sci. 4, 575-591. doi: $10.1039 / \mathrm{c} 5 \mathrm{bm} 00589 \mathrm{~b}$

Hao, R., Xing, R., Xu, Z., Hou, Y., Gao, S., and Sun, S. (2010). Synthesis, functionalization, and biomedical applications of multifunctional magnetic nanoparticles. Adv. Mater. 22, 2729-2742. doi: 10.1002/adma.201000260

Hashemikia, S., Hemmatinejad, N., Ahmadi, E., and Montazer, M. (2015). Optimization of tetracycline hydrochloride adsorption on amino modified SBA-15 using response surface methodology. J. Colloid. Interface. Sci. 443, 105-114. doi: 10.1016/j.jcis.2014.11.020

He, Q., and Shi, J. (2011). Mesoporous silica nanoparticle based nano drug delivery systems: synthesis, controlled drug release and delivery, pharmacokinetics and biocompatibility. J. Mater. Chem. 21, 5845-5855. doi: 10.1039/c0jm03851b

He, Q., Zhang, J., Shi, J., Zhu, Z., Zhang, L., Bu, W., et al. (2010). The effect of PEGylation of mesoporous silica nanoparticles on nonspecific binding of serum protein and cellular responses. Biomaterials 31, 1085-1092. doi: 10.1016/j.biomaterials.2009.10.046

He, Q., Zhang, Z., Gao, F., Li, Y., and Shi, J. (2011). In vivo biodistribution and urinary excretion of mesoporous silica nanoparticles: effects of particle size and PEGylation. Small 7, 271-280. doi: 10.1002/smll.201001459

He, Q., Zhang, Z., Gao, Y., Shi, J., and Li, Y. (2009). Intracellular localization and cytotoxicity of spherical mesoporous silica nano- and microparticles. Small 5, 2722-2729. doi: 10.1002/smll.200900923

He, X., Nie, H., Wang, K., Tan, W., Wu, X., and Zhang, P. (2008). In vivo study of biodistribution and urinary excretion of surface-modified silica nanoparticles. Anal. Chem. 80:9597-9603. doi: 10.1021/ac801882g

Hodali, H. A., Marzouqa, D. M., and Tekfa, F. Z. (2016). Evaluation of mesoporous silicate nanoparticles for the sustained release of the anticancer drugs 5fluorouracil and 7-hydroxycoumarin. J. Sol-Gel Sci. Technol. 80, 417-425. doi: $10.1007 /$ s10971-016-4127-8

Horcajada, P., Ramila, A., Perez-Pariente, J., and Vallet-Regi, M. (2004). Influence of pore size of MCM-41 matrices on drug delivery rate. Micropor. Mesopor. Mat. 68, 105-109. doi: 10.1016/j.micromeso.2003.12.012

Huang, X., Li, L., Liu, T., Hao, N., Liu, H., Chen, D., et al. (2011). The shape effect of mesoporous silica nanoparticles on biodistribution, clearance, and biocompatibility in vivo. ACS Nano 5, 5390-5399. doi: 10.1021/nn200365a

Huang, X., Teng, X., Chen, D., Tang, F., and He, J. (2010). The effect of the shape of mesoporous silica nanoparticles on cellular uptake and cell function. Biomaterials 31, 438-448. doi: 10.1016/j.biomaterials.2009.09.060

Hudson, S. P., Padera, R. F., Langer, R., and Kohane, D. S. (2008). The biocompatibility of mesoporous silicates. Biomaterials 29, 4045-4055. doi: 10.1016/j.biomaterials.2008.07.007

Izquierdo-Barba, I., Martinez, A., Doadrio, A. L., Perez-Pariente, J., and ValletRegi, M. (2005). Release evaluation of drugs from ordered three-dimensional silica structures. Eur. J. Pharm. Sci. 26, 365-373. doi: 10.1016/j.ejps.2005. 06.009

Jafari, S., Derakhshankhah, H., Alaei, L., Fattahi, A., Varnamkhasti, B. S., and Saboury, A. A. (2019). Mesoporous silica nanoparticles for therapeutic/diagnostic applications. Biomed. Pharmacother. 109, 1100-1111. doi: 10.1016/j.biopha.2018.10.167

Jin, D.-Y., and Yuan, J., Piper, J. (2011). “Long-lifetime luminescent nanobioprobes for advanced cytometry biosensing," in Nanotechnology in Australia: Showcase of Early Career Research (Singapore: Pan Stanford Publishing Pte. Ltd.), 317-345. doi: 10.1201/b11034-11

Kapczynski, A., Park, C., and Sampat, B. (2012). Polymorphs and prodrugs and salts (Oh My!): an empirical analysis of "secondary" pharmaceutical patents. PLoS ONE 7:e49470. doi: 10.1371/journal.pone.0049470

Kim, J., Kim, H. S., Lee, N., Kim, T., Kim, H., Yu, T., et al. (2008). Multifunctional uniform nanoparticles composed of a magnetic nanocrystal core and a mesoporous silica shell for magnetic resonance and fluorescence imaging and for drug delivery. Angew. Chem. Int. Ed. 47, 8438-8441. doi: 10.1002/anie.200802469
Kim, J., Lee, J. E., Lee, J., Yu, J. H., Kim, B. C., An, K., et al. (2006). Magnetic fluorescent delivery vehicle using uniform mesoporous silica spheres embedded with monodisperse magnetic and semiconductor nanocrystals. J. Am. Chem. Soc. 128, 688-689. doi: 10.1021/ja0565875

Kim, J., Li, W. A., Choi, Y., Lewin, S. A., Verbeke, C. S., Dranoff, G., et al. (2015). Injectable, spontaneously assembling, inorganic scaffolds modulate immune cells in vivo and increase vaccine efficacy. Nat. Biotechnol. 33, 64-72. doi: 10.1038/nbt.3071

Kresge, C. T., Leonowicz, M. E., Roth, W. J., Vartuli, J. C., and Beck, J. S. (1992). Ordered mesoporous molecular-sieves synthesized by a liquid-crystal template mechanism. Nature 359, 710-712. doi: 10.1038/359710a0

Kumar, P., Tambe, P., Paknikar, K. M., and Gajbhiye, V. (2018). Mesoporous silica nanoparticles as cutting-edge theranostics: advancement from merely a carrier to tailor-made smart delivery platform. J. Control. Release 10, 35-57. doi: 10.1016/j.jconrel.2018.08.024

Lai, C.-Y., Trewyn, B. G., Jeftinija, D. M., Jeftinija, K., Xu, S., Jeftinija, S., et al. (2003). A mesoporous silica nanosphere-based carrier system with chemically removable CdS caps for stimuli-responsive controlled release of neurotransmitters and drug molecules. J. Am. Chem. Soc. 125, 4451-4459. doi: $10.1021 /$ ja0286501

Lalchhingpuii, Tiwari, D., Lalhmunsiama, and Lee, S. M. (2017). Chitosan templated synthesis of mesoporous silica and its application in the treatment of aqueous solutions contaminated with cadmium (II) and lead (II). Chem. Eng. J. 328, 434-444. doi: 10.1016/j.cej.2017.07.053

Lammers, T., Kiessling, F., Hennink, W. E., and Storm, G. (2010). Nanotheranostics and image-guided drug delivery: current concepts and future directions. Mol. Pharm. 7, 1899-1912. doi: 10.1021/mp100228v

Lehto, V. P., Vaha-Heikkila, V., Paski, J., and Salonen, J. (2005). Use of thermoanalytical methods in quantification of drug load in mesoporous silicon microparticles. J. Therm. Anal. Calori. 80, 393-397. doi: 10.1007/s10973-005-0666-x

Lelong, G., Bhattacharyya, S., Kline, S., Cacciaguerra, T., Gonzalez, M. A., and Saboungi, M. L. (2008). Effect of surfactant concentration on the morphology and texture of MCM-41 materials. J. Phys. Chem. C 112, 10674-10680. doi: $10.1021 /$ jp800898n

Li, J., Shen, S., Kong, F., Jiang, T., Tang, C., and Yin, C. (2018). Effects of pore size on in vitro and in vivo anticancer efficacies of mesoporous silica nanoparticles. RSC Adv. 8, 24633-24640. doi: 10.1039/C8RA03914C

Li, L., Liu, T., Fu, C., Tan, L., Meng, X., and Liu, H. (2015). Biodistribution, excretion, and toxicity of mesoporous silica nanoparticles after oral administration depend on their shape. Nanomed. Nanotechnol. Biol. Med. 11, 1915-1924. doi: 10.1016/j.nano.2015.07.004

Li, Z., Barnes, J. C., Bosoy, A., Stoddart, J. F., and Zink, J. I. (2012). Mesoporous silica nanoparticles in biomedical applications. Chem. Soc. Rev. 41, 2590-2605. doi: $10.1039 / \mathrm{clcs} 15246 \mathrm{~g}$

Lin, H.-P., and Tsai, C.-P. (2003). Synthesis of mesoporous silica nanoparticles from a low-concentration CnTMAX-sodium silicate components. Chem. Lett. 32, 1092-1093. doi: 10.1246/cl.2003.1092

Lin, Y.-S., Abadeer, N., and Haynes, C. L. (2011). Stability of small mesoporous silica nanoparticles in biological media. Chem. Commun. 47, 532-534. doi: $10.1039 / \mathrm{c0cc} 02923 \mathrm{~h}$

Lin, Y.-S., and Hurley, K. R., Haynes C, L. (2012). Critical considerations in the biomedical use of mesoporous silica nanoparticles. Phys. Chem. Lett. 3, 364-374. doi: 10.1021/jz2013837

Lin, Y.-S., Tsai, C.-P., Huang, H.-Y., Kuo, C.-T., Hung, Y., Huang, D.-M., et al. (2005). Well-ordered mesoporous silica nanoparticles as cell markers. Chem. Mater. 17, 4570-4573. doi: 10.1021/cm051014c

Lin, Y.-S., Wu, S.-H., Hung, Y., Chou, Y.-H., Chang, C., Lin, M.-L., et al. (2006). Multifunctional composite nanoparticles: magnetic, luminescent, and mesoporous. Chem. Mater. 18, 5170-5172. doi: 10.1021/cm061976z

Liu, B., Li, C., Cheng, Z., Hou, Z., Huang, S., and Lin, J. (2016). Functional nanomaterials for near-infrared-triggered cancer therapy. Biomater. Sci. 4, 890-909. doi: 10.1039/c6bm00076b

Lucky, S. S., Soo, K. C., and Zhang, Y. (2015). Nanoparticles in photodynamic therapy. Chem. Rev. 115, 1990-2042. doi: 10.1021/cr5004198

Mai, W. X., and Meng, H. (2013). Mesoporous silica nanoparticles: a multifunctional nano therapeutic system. Integr. Biol. 5, 19-28. doi: $10.1039 / \mathrm{c} 2 \mathrm{ib} 20137 \mathrm{~b}$ 
Maleki, A., and Hamidi, M. (2016). "Nanoarchitectured mesoporous silica-based drug-delivery systems: toward perfect nanomedicine," in Nanoarchitectonics for Smart Delivery and Drug Targeting (Cambridge, MA: Elsevier), 345-377. doi: 10.1016/B978-0-323-47347-7.00013-6

McCarthy, J., Inkielewicz-Stepniak, I., Corbalan, J. J., and Radomski, M. W. (2012). Mechanisms of toxicity of amorphous silica nanoparticles on human lung submucosal cells in vitro: protective effects of fisetin. Chem. Res. Toxicol. 25, 2227-2235. doi: 10.1021/tx3002884

Meng, H., Xue, M., Xia, T., Ji, Z., Tarn, D. Y., Zink, J. I., et al. (2011). Use of size and a copolymer design feature to improve the biodistribution and the enhanced permeability and retention effect of doxorubicin-loaded mesoporous silica nanoparticles in a murine xenograft tumour model. ACS Nano. 5, 4131-4144. doi: $10.1021 / \mathrm{nn} 200809 \mathrm{t}$

Miricioiu, M. G., Iacob, C., Nechifor, G., and Niculescu, V. C. (2019). High selective mixed membranes based on mesoporous MCM-41 and MCM-41- $\mathrm{NH}_{2}$ particles in a polysulfone matrix. Front. Chem. 7:332. doi: $10.3389 /$ fchem. 2019.00332

Monnier, C. A., Burnand, D., Rothen-Rutishauser, B., Lattuada, M., and Petri-Fink, A. (2014). Magnetoliposomes: opportunities and challenges. Eur. J. Nanomed. 6, 201-215. doi: 10.1515/ejnm-2014-0042

Munoz, B., Ramila, A., Perez-Pariente, J., Diaz, I., and Vallet-Regi, M. (2003). MCM-41 organic modification as drug delivery rate regulator. Chem. Mater. 15, 500-503. doi: $10.1021 / \mathrm{cm} 021217 \mathrm{q}$

Napierska, D., Thomassen, L. C. J., Rabolli, V., Lison, D., Gonzalez, L., KirschVolders, M., et al. (2009). Size-dependent cytotoxicity of monodisperse silica nanoparticles in human endothelial cells. Small 5, 846-853. doi: $10.1002 /$ smll.200800461

Navarro-Tovar, G., Palestino, G., and Rosales-Mendoza, S. (2016). An overview on the role of silica-based materials in vaccine development. Expert Rev. Vaccines. 15, 1449-1462. doi: 10.1080/14760584.2016.1188009

Nel, A. E., Madler, L., Velegol, D., Xia, T., Hoek, E. M. V., Somasundaran, P., et al. (2009). Understanding biophysicochemical interactions at the nano-bio interface. Nat. Mater. 8, 543-557. doi: 10.1038/nmat2442

Niculescu, V. C., Ene, R., and Parvulescu, V. (2011). An overview of the synthesis, characterization techniques and applications of silica mesoporous materials. Progress Cryogenics Isotopes Separa. 14, 111-120.

Niculescu, V. C., Paun, G., and Parvulescu, V. (2018). New organometallic complex supported on mesoporous silica and its enzymes activity inhibition properties. Appl. Organomet. Chem. 32:e4590. doi: 10.1002/aoc.4590

Nishimori, H., Kondoh, M., Isoda, K., Tsunoda, S., Tsutsumi, Y., and Yagi, K. (2009). Silica nanoparticles as hepatotoxicants. Eur. J. Pharm. Biopharm. 72, 496-501. doi: 10.1016/j.ejpb.2009.02.005

Oshima, S., Perera, J. M., Northcott, K. A., Kokusen, H., Stevens, G. W., and Komatsu, Y. (2006). Adsorption behaviour of Cadmium(II) and Lead(II) on mesoporous silicate MCM-41. Sep. Sci. Technol. 41, 1635-1643. doi: $10.1080 / 01496390600674786$

Ow, H., Larson, D. R., Srivastava, M., Baird, B. A., Webb, W. W., and Wiesner, U. (2005). Bright and stable core-shell fluorescent silica nanoparticles. Nano Lett. 5, 113-117. doi: $10.1021 / \mathrm{nl} 0482478$

Pan, J., Wan, D., and Gong, J. (2011). PEGylated liposome coated QDs/mesoporous silica core-shell nanoparticles for molecular imaging. Chem Commun. 47, 3442-3444. doi: 10.1039/c0cc05520d

Pang, X. L., and Tang, F. Q. (2005). Morphological control of mesoporous materials using inexpensive silica sources. Micropor Mesopor Mater. 85, 1-6. doi: 10.1016/j.micromeso.2005.06.012

Peer, D., Karp, J. M., Hong, S., Farokhzad, O. C., Margalit, R., and Langer, R. (2007). Nanocarriers as an emerging platform for cancer therapy. Nat. Nanotechnol. 2, 751-760. doi: 10.1038/nnano.2007.387

Rosenholm, J. M., Sahlgren, C., and Linden, M. (2010). Towards mutifunctional, targeted drug delivery systems using mesoporous silica nanoparticlesopportunities \& challenges. Nanoscale 2, 1870-1883. doi: 10.1039/c0nr $00156 \mathrm{~b}$

Rosenholm, J. M., Sahlgren, C., and Lindén, M. (2011). Multifunctional mesoporous silica nanoparticles for combined therapeutic, diagnostic and targeted action in cancer treatment. Curr. Drug Targets. 12, 1166-1186. doi: $10.2174 / 138945011795906624$

Roy, I., Ohulchanskyy, T. Y., Pudavar, H. E., Bergey, E. J., Oseroff, A. R., Morgan, J., et al. (2003). Ceramic-based nanoparticles entrapping water-insoluble photosensitizing anticancer drugs: a novel drug-carrier system for photodynamic therapy. J. Am. Chem. Soc. 125, 7860-7865. doi: $10.1021 /$ ja0343095

Santos, H. A., Salonen, J., Bimbo, L. M., Lehto, V.-P., Peltonen, L., and Hirvonen, J. (2015). Mesoporous materials as controlled drug delivery formulations. J. Drug. Deliv. Sci. Technol. 21, 139-155. doi: 10.1016/S1773-2247(11)50016-4

Santra, S., Wang, K., Tapec, R., and Tan, W. (2001b). Development of novel dye-doped silica nanoparticles for biomarker application. J. Biomed. Optic. 6, 160-166. doi: 10.1117/1.1353590

Santra, S., Zhang, P., Wang, K., Tapec, R., and Tan, W. (2001a). Conjugation of biomolecules with luminophore-doped silica nanoparticles for photostable biomarkers. Anal. Chem. 73, 4988-4993. doi: 10.1021/ac010406+

Sanvicens, N., and Marco, M. P. (2008). Multifunctional nanoparticles properties and prospects for their use in human medicine. Trends Biotechnol. 26, 425-433. doi: 10.1016/j.tibtech.2008.04.005

Schlossbauer, A., Kecht, J., and Bein, T. (2009). Biotin-avidin as a proteaseresponsive cap system for controlled guest release from colloidal mesoporous silica. Angew. Chem. Int. Ed. 48, 3092-3095. doi: 10.1002/anie.200805818

Sercombe, L., Veerati, T., Moheimani, F., Wu, S. Y., Sood, A. K., and Hua, S. (2015). Advances and challenges of liposome assisted drug delivery. Front. Pharmacol. 6:286. doi: $10.3389 /$ fphar.2015.00286

Shang, L., Nienhaus, K., and Nienhaus, G. (2014). Engineered nanoparticles interacting with cells: size matters. J. Nanobiotechnol. 12:5. doi: 10.1186/1477-3155-12-5

Shen, S.-C., Dong, Y., Letchmanan, K., and Ng, W. K. (2017). "Mesoporous materials and technologies for development of oral medicine" in The Micro and Nano Technologies, Nanostructures for Oral Medicine, eds E. Andronescu, and A. M. Grumezescu (Cambridge, MA: Elsevier Inc.), 699-749. doi: 10.1016/B978-0-323-47720-8.00024-9

Shi, S. X., Chen, F., and Cai, W. B. (2013). Biomedical applications of functionalized hollow mesoporous silica nanoparticles: focusing on molecular imaging. Nanomedicine. 8, 2027-2039. doi: 10.2217/nnm.13.177

Slowing, I. I., Wu, C. W., Vivero-Escoto, J. L., and Lin, V. S. (2009). Mesoporous silica nanoparticles for reducing hemolytic activity towards mammalian red blood cells. Small 5, 57-62. doi: 10.1002/smll.200800926

Soenen, S. J., Velde, G. V., Ketkar-Atre, A., Himmelreich, U., and De Cuyper, M. (2011). Magnetoliposomes as magnetic resonance imaging contrast agents. Wiley Interdiscip. Rev. Nanomed. Nanobiotechnol. 3, 197-211. doi: 10.1002/wnan.122

Song, S. W., Hidajat, K., and Kawi, S. (2005). Functionalized SBA-15 materials as carriers for controlled drug delivery: influence of surface properties on matrix-drug interactions. Langmuir 21, 9568-9575. doi: 10.1021/la051167e

Stober, W., Fink, A., and Bohn, E. (1968). Controlled growth of monodisperse silica spheres in the micron size range. J. Colloid Interface Sci. 26, 62-69. doi: 10.1016/0021-9797(68)90272-5

Strebhardt, K., and Ullrich, A. (2008). Paul Ehrlich's magic bullet concept: 100 years of progress. Nat. Rev. Cancer 8, 473-480. doi: 10.1038/nrc2394

Suschek, C. V., Bonmann, E., Kapsokefalou, A., Hemmrich, K., Kleinert, H., Forstermann, U., et al. (2002). Revisiting an old antimicrobial drug: amphotericin B induces interleukin-1-converting enzyme as the main factor for inducible nitric-oxide synthase expression in activated endothelia. Mol. Pharmacol. 62, 936-946. doi: 10.1124/mol.62.4.936

Sutewong, T., Sai, H., Cohen, R., Wang, S., Bradbury, M., Baird, B., et al. (2011). Highly aminated mesoporous silica nanoparticles with cubic pore structure. J. Am. Chem. Soc. 133, 172-175. doi: 10.1021/ja1061664

Suzuki, K., Ikari, K., and Imai, H. (2004). Synthesis of silica nanoparticles having a well-ordered mesostructure using a double surfactant system. J. Am. Chem. Soc. 126, 462-463. doi: 10.1021/ja038250d

Tan, T. T., Selvan, S. T., Zhao, L., Gao, S., and Ying, J. Y. (2007). Size control, shape evolution, and silica coating of near-infrared-emitting PbSe quantum dots. Chem. Mater. 19, 3112-3117. doi: 10.1021/cm061974e

Tang, F., Li, L., and Chen, D. (2012). Mesoporous silica nanoparticles: synthesis, biocompatibility and drug delivery. Adv. Mater. 24, 1504-1534. doi: 10.1002/adma.201104763

Thomas, C. R., Ferris, D. P., Lee, J. H., Choi, E., Cho, M. H., Kim, E. S, et al. (2010). Noninvasive remote-controlled release of drug molecules in vitro using magnetic actuation of mechanized nanoparticles. J. Am. Chem. Soc. 132, 10623-10625. doi: 10.1021/ja1022267 
Tourne-Peteilh, C., Lerner, D. A., Charnay, C., Nicole, L., Begu, S., and Devoisselle, J. M. (2003). The potential of ordered mesoporous silica for the storage of drugs: the example of a pentapeptide encapsulated in a MSU-tween 80. Chemphyschem 4, 281-286. doi: 10.1002/cphc.200390045

Trewyn, B. G., Nieweg, J. A., Zhao, Y., and Lin, V. S. Y. (2008). Biocompatible mesoporous silica nanoparticles with different morphologies for animal cell membrane penetration. Chem. Eng. J. 137, 23-29. doi: 10.1016/j.cej.2007.09.045

Vallet-Regi, M., Balas, F., and Arcos, D. (2007). Mesoporous materials for drug delivery. Angew. Chem. Int. Ed. 46, 7548-7558. doi: 10.1002/anie.200604488

Vallet-Regi, M., Doadrio, J. C., Doadrio, A. L., Izquierdo-Barba, I., and PerezPariente, J. (2004). Hexagonal ordered mesoporous material as a matrix for the controlled release of amoxicillin. Solid State Ionics. 172, 435-439. doi: 10.1016/j.ssi.2004.04.036

Vallet-Regi, M., Ramila, A., del Real, R. P., and Perez-Pariente, J. (2001). A new property of MCM-41: drug delivery system. Chem. Mater. 13, 308-311. doi: $10.1021 / \mathrm{cm} 0011559$

Vanblaaderen, A., and Vrij, A. (1992). Synthesis and characterization of colloidal dispersions of fluorescent, monodisperse silica spheres. Langmuir 8, 2921-2931. doi: 10.1021/la00048a013

Vazquez, N. I., Gonzalez, Z., Ferrari, B., and Castro, Y. (2017). Synthesis of mesoporous silica nanoparticles by sol-gel as nanocontainer for future drug delivery applications. Bol. Soc. Esp. Ceram. V 56, 139-145. doi: 10.1016/j.bsecv.2017.03.002

Verma, A., and Stellacci, F. (2010). Effect of surface properties on nanoparticle-cell interactions. Small 6, 12-21. doi: 10.1002/smll.200901158

Wang, H., Van Der Voort, P., Qu, H., and Liu, S. (2013). A simple roomtemperature synthesis of mesoporous silica rods with tuneable size and porosity. J. Nanoparticle Res. 15:1501. doi: 10.1007/s11051-013-1501-0

Wang, L.-S., Wu, L.-C., Lu, S.-Y., Chang, L.-L., Teng, I.-T., Yang, C.-M., et al. (2010). A. biofunctionalized phospholipid-capped mesoporous silica nanoshuttles for targeted drug delivery: improved water suspensibility and decreased nonspecific protein binding. ACS Nano. 4, 4371-4379. doi: $10.1021 / \mathrm{nn} 901376 \mathrm{~h}$

Wang, S. (2009). Ordered mesoporous materials for drug delivery. Micropor. Mesopor. Mat. 117, 1-9. doi: 10.1016/j.micromeso.2008.07.002

Wang, T. Y., Jiang, H., Zhao, Q., Wang, S., Zou, M., and Cheng, G. (2012). Enhanced mucosal and systemic immune responses obtained by porous silica nanoparticles used as an oral vaccine adjuvant: effect of silica architecture on immunological properties. Int. J. Pharm. 436, 351-358. doi: 10.1016/j.ijpharm.2012.06.028

Wang, Y., Zhao, Q., Han, N., Bai, L., Li, J., Liu, J., et al. (2015). Mesoporous silica nanoparticles in drug delivery and biomedical applications. Nanomedicine 11, 313-327. doi: 10.1016/j.nano.2014.09.014

Wartenberg, N., Fries, P., Raccurt, O., Guillermo, A., Imbert, D., and Mazzanti, M. (2013). A gadolinium complex confined in silica nanoparticles as a highly efficient T1/T2 MRI contrast agent. Chem. A Eur. J. 19, 6980-6983. doi: 10.1002/chem.201300635

Wu, L., Mendoza-Garcia, A., Li, Q., and Sun, S. (2016). Organic phase syntheses of magnetic nanoparticles and their applications. Chem. Rev. 116, 10473-10512. doi: 10.1021/acs.chemrev.5b00687

Wu, S.-H., Lin, Y.-S., Hung, Y., Chou, Y.-H., Hsu, Y.-H., Chang, C., et al. (2008). Multifunctional mesoporous silica nanoparticles for intracellular labeling and animal magnetic resonance imaging studies. ChemBioChem 9, 53-57. doi: 10.1002/cbic.200700509

Xie, J., Lee, S., and Chen, X. (2010). Nanoparticle-based theranostic agents. $A d v$. Drug Delivery Rev. 62, 1064-1079. doi: 10.1016/j.addr.2010.07.009

Xu, W., Riikonen, J., and Lehto, V. P. (2012). Mesoporous systems for poorly soluble drugs. Int. J. Pharm. 30, 181-197. doi: 10.1016/j.ijpharm.2012.09.008

Yanagisawa, T., Shimizu, T., Kuroda, K., and Kato, C. (1990). The preparation of alkyltrimethylammonium-kanemite complexes and their conversion to microporous materials. Bull. Chem. Soc. Jpn. 63, 988-992. doi: $10.1246 /$ bcsj.63.988

Yang, G., Phua, S. Z. F., Bindra, A. K., and Zhao, Y. (2019). Degradability and clearance of inorganic nanoparticles for biomedical applications. Adv. Mater. 31:1805730. doi: 10.1002/adma.201805730

Yoo, H., and Pak, J. (2013). Synthesis of highly fluorescent silica nanoparticles in a reverse microemulsion through double-layered doping of organic fluorophores. J. Nanopart. Res. 15:1609. doi: 10.1007/s11051-013-1609-2

Yuan, L., Tang, Q., Yang, D., Zhang, J. Z., Zhang, F., and Hu, J. (2011). Preparation of $\mathrm{pH}$-responsive mesoporous silica nanoparticles and their application in controlled drug delivery. J. Phys. Chem. C 115, 9926-9932. doi: 10.1021/jp201053d

Zelenak, V., Hornebecq, V., and Llewellyn, P. (2005). Zinc(II)-benzoato complexes immobilised in mesoporous silica host. Micropor. Mesopor. Mat. 83, 125-135. doi: 10.1016/j.micromeso.2005.03.022

Zeng, W., Qian, X. F., Zhang, Y. B., Yin, J., and Zhu, Z. K. (2005). Organic modified mesoporous MCM-41 through solvothermal process as drug delivery system. Mater. Res. Bull. 40, 766-772. doi: 10.1016/j.materresbull.2005.02.011

Zhang, J., Chen, M., Zhao, X., Zhang, M., Mao, J., Cao, X., et al. (2018) Controlled and localized delivery of c-myc AS-ODN to cells by 3-aminopropyltrimethoxylsilane modified SBA-15 mesoporous silica. AIP Adv. 8:015220. doi: 10.1063/1.5012535

Zhao, D. Y., Feng, J. L., Huo, Q. S., Melosh, N., Fredrickson, G. H. Chmelka, B. F., et al. (1998). Triblock copolymer syntheses of mesoporous silica with periodic 50 to 300 angstrom pores. Science 279, 548-552. doi: $10.1126 /$ science. 279.5350 .548

Zhao, X. J., Bagwe, R. P., and Tan, W. H. (2004). Development of organic-dyedoped silica nanoparticles in a reverse microemulsion. Adv. Mater. 16, 173-176. doi: 10.1002/adma.200305622

Zhao, Z. X., Huang, Y. Z., Shi, S. G., Tang, S. H., Li, D. H., and Chen, X. L. (2014). Cancer therapy improvement with mesoporous silica nanoparticles combining photodynamic and photothermal therapy. Nanotechnology 25:285701. doi: 10.1088/0957-4484/25/28/285701

Conflict of Interest: The author declares that the research was conducted in the absence of any commercial or financial relationships that could be construed as a potential conflict of interest.

Copyright (c) 2020 Niculescu. This is an open-access article distributed under the terms of the Creative Commons Attribution License (CC BY). The use, distribution or reproduction in other forums is permitted, provided the original author(s) and the copyright owner(s) are credited and that the original publication in this journal is cited, in accordance with accepted academic practice. No use, distribution or reproduction is permitted which does not comply with these terms. 